\title{
NILAI-NILAI PENDIDIKAN TAUHID DALAM KISAH ASHABUL UKHDUD SURAT AL-BURUJ PERSPEKTIF IBN KATSIR DAN HAMKA
}

\author{
Muthoifin ${ }^{1}$, Fahrurozi ${ }^{2}$ \\ ${ }^{1}$ Fakultas Agama Islam Universitas Muhammadiyah Surakarta \\ ${ }^{2}$ Akademi Dakwah Indonesia \\ Dewan Dakwah Islamiyah Indonesia Jawa Tengah \\ E-Mail: mut122@ums.ac.id, jalanku85@gmail.com
}

\begin{abstract}
Tawhed is to insulate God in creation, worship and name and natures. he must be awake with the best of everything that can divert it. Because tawhed is a very basic and fundamental thing for a Muslim's life. Tawhid is the determinant of a person both in the life of the world and the hereafter, happy or miserable, safe or wretched. tawhed became one of the potential that brought every human being when he was born in the world, the need for educational efforts so that potential is maintained. This study aims to determine the concept of tawhed education in the story of ashabul ukhdud. So important is the story that Allah mentioned in the Qur'an. The second goal is to implement the concepts of Tawhed education in Islamic education. Because the most important element in Islamic education is tawhed education, education that teaches every practice, behavior, purpose of life is only God. The results showed that the ideal Islamic education is very concerned about the implementation of tawhid education, because tawhed is the spirit of Islamic education which consists of three principal, first, tawhed rububiyyah education contained therein such as human nature as the basis of tawhed education, the natural sign as a means of tawhed education, reward and punismant in tawhed education. Secondly, the education of tawhed uluhiyyah such as, the role of educators in tawhid education, evaluation in tawhed education and tawhed education throughout life. Then the third tawhid asthma 'wasifat (names and natures of Allah) education.
\end{abstract}

Keyword: education; tawhed; ashabul ukhdud

\begin{abstract}
Abstrak: Tauhid yaitu mengesakan Allah dalam rububiyyah, uluhiyyah dan asma' washifat, harus terjaga dengan sebaik-baiknya dari segala yang bisa menyelewengkannya. Karena tauhidmerupakan perkara yang sangat pokok dan mendasar bagi kehidupan seorang muslim. Tauhid merupakan penentu seseorang baik di kehidupan dunia maupun akhirat, bahagia atau sengsara, selamat atau celaka. Tauhid menjadi salah satu potensi yang dibawa setiap manusia ketika ia dilahirkan didunia, perlu adanya usaha pendidikan agar potensi itu tetap terjaga. Penelitian ini bertujuan untuk mengetahui konsep pendidikan tauhid dalam kisah ashabul ukhdud. Begitu pentingnya kisah tersebut sehingga Allah menyebutkannya dalam AlQur'an. Tujuan kedua yaitu untuk mengimplemen-tasikan konsep-konsep pendidikan tauhid dalam pendidikan Islam. Karena unsur terpenting dalam pendidikan Islam adalah pendidikan tauhid, pendidikan yang mengajarkan setiap amalan, perilaku, tujuan hidup hanya Allah. Hasil penelitian menunjukkan bahwa pendidikan Islam yang ideal sangatlah memperhatikan pelaksanaan pendidikan tauhid, karena tauhid merupakan ruh dari pendidikan Islam yang terdiri dari tiga pokok, pertama, pendidikan tauhid rububiyyah yang terkandung didalamnya seperti fitrah manusia sebagai dasar pendidkan tauhid, ayat kauniah sebagai sarana pendidikan tauhid, Targhib dan tarhib dalam pendidikan tauhid. Kedua, pendidikan tauhid uluhiyyah seperti, peran pendidik dalam pendidikan tauhid, evaluasi dalam pendidikan tauhid dan pendidikan sepanjang hayat. Kemudian yang ketiga pendidikan tauhid asma' wasifat.
\end{abstract}

Kata kunci: nilai; pendidikan; tauhid; ashabul ukhdud, al-buruj. 


\section{PENDAHULUAN}

Ajaran Islam mengajak manusia untuk meyakini bahwa semesta alam ini ada yang menciptakan. Karena pada dasarnya sesuatu itu ada karena ada yang merancangnya, membentuknya dan membuatnya. Secara logika akal sehat manusia, tidak mungkin sesuatu itu ada dengan sendirinya, tiba-tiba muncul tanpa sebab yang menjadikannya sesuatu itu ada. Allah Ta'ala yang menciptakan alam ini sehingga ia ada dan berkembang. Allah Ta'ala juga yang menyusun dan mengaturnya begitu selaras tanpa ada cacat. ${ }^{1}$ Meyakini bahwa hanya Allah Ta'ala yang menciptakan seluruh alam semesta ini dari ketiadaan menjadi ada itulah yang disebut dengan tauhid.

Para Nabi dan Rasul dari zaman dahulu hingga Rasul terakhir yakni Muhammad Shalallahu alaihi wasallam membawa satu misi dasar yang sama yaitu risalah tauhid atau konsep tauhid. Akan tetapi konsep tauhid sudah menyimpang dari yang sebenarnya. Penyimpangan dari konsep tauhid yang benar dan lurus sudah terjadi sejak dahulu, dan berkembang hingga sekarang.

Zaman modern sekarang ini, penyimpangan konsep tauhid dan aqidah sungguh sangat jauh. Sejauh jarak masa sekarang dan masa terjadinya awal penyimpangan. Penyimpangan bukan hanya sekedar dalam masalah aqidah dan ibadah, ia menjalar hingga masalah kehidupan sehari-hari bahkan semua masalah kehidupan tidak luput dari penyimpangan tauhid.

Setiap bangsa dan suku mempunyai kebiasaan dan tradisi yang turun-temurun dari nenek moyang mereka. Itulah yang disebut sebagai adat istiadat. Banyak sekali penyimpangan dalam adat istiadat, setiap suku mempunyai adat tersendiri. Suku jawa yang mempunyai adat lebih cenderung kepada Hindu-Budha percaya kepada sesaji yang bertujuan untuk menjamu arwah atau para dewa. Ritual ruwatan yang mengagungkan Nyi Roro Kidul

1 Shalih Bin Fauzan.Kitab Tauhid, (Akafa Press; Jakarta, 1998) jilid 1, hlm. 39 yang dipercaya bisa memberi manfaat dan madharat. Ritual proses kehamilan calon bayi hingga melahirkan seperti selametan, ruwatan, nyadran, tirakatan, mitoni bagi calon bayi yang mau lahir, menanam ariari didepan rumah, diberi bumbu-bumbu, mantera dan lampu penerang.

Praktek pesugihan yang luar biasa aktifitasnya, bahkan disediakan tempat yang layak dan mempunyai fasilitas yang sangat mendukung. Keyakinan yang mengaitkan antara suatu kejadian dengan peristiwa tertentu atau yang disebut dengan tathoyyur menjadi hal yang umum. Seperti burung gagak yang berputar-putar diatas awan menandakan ada orang mati. Mempercayai hari-hari sial yang tidak boleh melakukan acara atau pesta pada hari itu, dikhawatirkan akan terjadi sesuatu yang tidak diinginkan.

Dukun memegang peran sentral dalam masalah penyimpangan ini. Karena pada hakekatnya dukunlah yang mengajak manusia kepada jalan setan. Ia merupakan kaki-tangan jin dan setan dalam menyesatkan manusia. Perdukunan merupakan fenomena yang ada sejak dahulu. Menurut pandangan sebagian orang, dukun dapat menyelesaikan masalah yang dihadapinya. Dukun merupakan orang yang serba mengetahui segala hal. Perjodohan, pernikahan, keluarga, rizki, kebahagiaan, nasib, waktu baik dan waktu buruk. Sehingga sebutan yang umum bagi dukun dan tukang ramal adalah 'orang pintar'. Keyakinan semacam ini sudah menjadi perkara yang lumrah dan biasa terjadi dimasyarakat. Padahal sudah jelas Rasulullah melarang percaya kepada dukun, Ia bersabda:

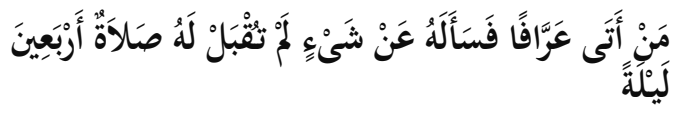

"Barang siapa mendatangi dukun dan menanyakan suatu hal padanya maka tidak diterima sholatnya selama 40 hari. $^{\prime 2}$

2 Muslim, Shahih Muslim,(Dar Al-Hadist; Kairo,2010) Hadist No. 5957 
Masih banyak contoh-contoh yang tidak mungkin dipaparkan semuanya. Mereka percaya dengan mitos-mitos yang berputar sekitar ritual dan adat tersebut seperti kebahagiaan, kesedihan, bencana, anugerah, susah, senang dan lain-lain. Keyakinan seperti itu jelas merupakan penyimpangan dari tauhid. Karena meyakini ada sesuatu yang lain yang dapat memberikan, menahan, menentukan rizki, merubah nasib selain Allah Ta'ala.

Dunia pendidikan dan ilmu pengetahuan telah terjadi penyimpangan dari konsep tauhid sudah lama berlangsung. Salah satu buktinya adalah konsep Darwin dalam kejadian alam semesta yang disebut dengan teori evolusi. Darwinis menyatakan bahwa manusia modern saat ini berevolusi dari makhluk serupa kera. Menurut mereka, selama proses evolusi yang diperkirakan berawal empat sampai lima juta tahun lalu, terdapat beberapa "bentuk transisi" antara manusia modern dan nenek moyangnya. Menurut skenario yang sepenuhnya rekaan ini, terdapat empat "kategori" dasar: australopithecus, homo habilis, homo erectus, homo sapiens. ${ }^{3}$

Pendapat mereka menyatakan bahwa nenek moyang manusia adalah kera yang berevolusi menjadi manusia. Mereka hanya percaya pada materi dan tidak percaya pada non-materi. Sebetulnya, pendapat seperti ini sudah dibantah oleh para ilmuan dengan hasil riset dan penelitian yang mendalam. Tidak mungkin sesuatu yang sudah didesain sedemikian detail dan sempurna tidak ada yang merancang. Muncul secara evolusi yang membutuhkan bukti yang tidak pernah ditemukan hingga sekarang. Paham darwinisme merupakan paham yang tidak meyakini adanya pencipta yaitu Allah. Dan parahnya, paham tersebut masih dipelajari dan menjadi kurikulum pendidikan nasional hingga sekarang.

Aliran-aliran pemikiran yang berkembang pada saat ini membawa pada kesimpulan bahwa tauhid bagi

3 Harun Yahya. Runtuhnya Teori Evolusi, ( Dzikra; Bandung, 2001) ,hlm. 215 seorang muslim itu tidak mutlak. Seperti pemahaman relatifisme yang berkembang dari liberalisme. Paham relatifisme beranggapan bahwa kebenaran dalam ajaran agama Islam itu belum tentu benar jika dilihat dari ajaran agama lain. Agama Islam itu bukan satu-satunya agama yang benar, Allah itu bukan satu-satunya illah yang berhak untuk disembah. Maka paham liberalisme ini menyatakan bahwa semua agama sama, sama-sama memiliki tuhan, sama-sama benarnya. Hal ini berimplikasi kepada praktek beragama dimasyarakat yang keluar jauh dari jalan syariat yang benar. Islam menerima adanya perbedaan dalam masalah agama, tapi tidak membenarkan semua agama itu sama (pluralisme agama). ${ }^{4}$

Disisi lain dari paham-paham yang menyimpang, para dai dan ustadz penyeru kepada tauhid dan aqidah yang benar mendapat perlakuan yang tidak adil. Mereka menyeru ummat untuk hati-hati terhadap paham dan aqidah yang menyimpang di cap sebagai provokator, anti terhadap kebersaman dan kerukunan. Bahkan banyak dari mereka masuk jeruji tahanan karena tegas dan teguh terhadap paham tauhid yang mengakar dijiwa mereka. Apa yang mereka serukan merupakan kebenaran yang diopinikan oleh penguasa sebagai kejahatan serta melabelinya dengan sesuatu yang tidak masuk akal. Mereka dipersekusi, diintimidasi, diteror dengan berbagai cara agar dakwah mereka tertahan. Seperti inilah apa yang dialami oleh rahib, ghulam dan orang-orang yang beriman dalam kisah ashabul ukhdud. Semangat untuk menyerukan kepada tauhid akan selalu ada sepanjang zaman selama masih ada kaum muslimin yang lurus, istiqamah dan berpegang teguh pada tauhid.

Memperhatikan penyimpanganpenyimpangan tersebut, maka pendidikan tauhid sangatlah urgen bagi individu dan masyarakat. Disamping minimnya

4 Tim Insist. Isu-isu Sentral dalam Pemikiran Islam Liberal. https://insists.id/isu-isu-sentral-dalam-pemikiran-islam-liberal/. Diakses 22 Oktober 2018, pukul 11:24 
pendidikan agama disekolah, pendidikan tauhid hanya bagian kecil dari materi pendidikan agama yang diajarkan kepada murid-murid.Para ulama mencatat betapa pentingnya tauhid yang benar untuk menjaga keimanan dan ibadah kepada Allah. Tauhid merupakan syarat diterimanya semua ibadah, apapun ibadah yang dikerjakan tanpa didasari dengan tauhid maka akan sia-sia. ${ }^{5}$ Tauhid juga merupakan pilar penopang utama untuk taat kepada Allah. Karena orang yang bertauhid itu beramal karena Allah, untuk Allah, baik beramal secara sembunyisembunyi atau terang-terangan. Adapun orang yang tidak bertauhid seperti orang yang riya', ia bersedekah, shalat, berzikir jika ada orang yang melihat didekatnya. Orang yang bertauhid itu merasa aman dan tenang, serta mereka mendapat petunjuk dari Allah. ${ }^{6}$

Al-Qur'an memberikan petunjuk tentang pendidikan tauhid sangatlah banyak, terutama pada surat-surat makkiyah. Salah satunya dalam suratAl-Buruj yang menceritakan kisah Ashabul Ukhdud. Kisah Ashabul Ukhdud merupakan kisah perjuangan orang-orang yang bertauhid memperjuangkan aqidah dan keimanan mereka dengan teguh dan tegar. Demi mempertahankan ketauhidan mereka, mereka rela mengorbankan jiwa dan harta bahkan nyawa.

Kisah perjuangan Ashabul Ukhdud banyak mengandung pelajaran dan hikmah yang bisa digali. Itulah sebabnya sehingga Allah mengabadikan kisah mereka didalam Al-Qur'an. Allah berfirman:

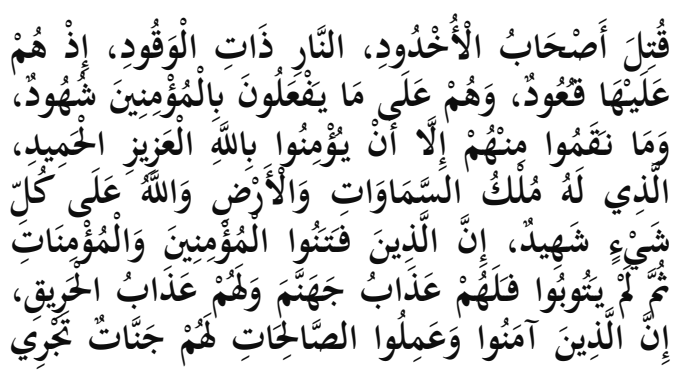

5 Shalih Bin Fauzan.Kitab Tauhid, (Akafa Press; Jakarta, 1998) jilid 1, hlm. 87-88

6 Al-Utsaimin.Al-Qaul Al-Mufid, (Dar Ibn Aljauzy; Arab Saudi, 1424) hlm. 61

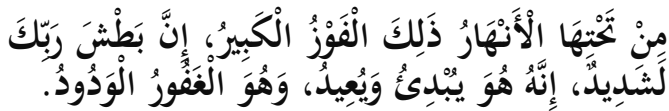

"Binasa dan terlaknatlah orang-orang yang membuat parit, yang berapi (dinyalakan dengan) kayu bakar, ketika mereka duduk di sekitarnya, sedang mereka menyaksikan apa yang mereka perbuat terhadap orangorang yang beriman. Dan mereka tidak menyiksa orang-orang mukmin itu melainkan karena orang-orang mukmin itu beriman kepada Allah Yang Maha Perkasa lagi Maha Terpuji, Yang mempunyai kerajaan langit dan bumi; dan Allah Maha Menyaksikan segala sesuatu. Sesungguhnya orang-orang yang mendatangkan cobaan kepada orang-orang yang mukmin laki-laki dan perempuan kemudian mereka tidak bertaubat, maka bagi mereka azab Jahannam dan bagi mereka azab (neraka) yang membakar.Sesungguhnya orang-orang yang beriman dan beramal shalih bagi mereka jannah yang mengalir dibawahnya sungai-sungai, itulah kemenangan yang besar. Sesungguhnya azab Tuhanmu benar-benar keras. Sesungguhnya Dialah Yang menciptakan (makhluk) dari permulaan danmenghidup-kannya (kembali). Dialah Yang Maha Pengampun lagi Maha Pengasih."7

Ibnu Katsir menjelaskan bahwa tidaklah mereka memiliki dosa kecuali hanya beriman kepada Allah yang Maha Perkasa, Maha Pencegah lagi Maha Terpuji dalam segala perkataan, perbuatan, syariat dan taqdirNya. Meskipun Allah mentaqdirkan hambaNya tertangkap dan tersiksa ditangan orang-orang kafir, maka Allah tetap Maha Perkasa dan Maha Terpuji.Yang demikian banyak manusia tidak mengetahui sebab mengapa hal tersebut terjadi. ${ }^{8}$

Kisah Ashabul Ukhdud berawal dari seorang anak muda (ghulam) yang belajar ilmu sihir dan ilmu agama, ia menghadapi dengan kebatilan dan keimanan. Ia memilih

7 Al-Qur'an Surat Al-Buruj ayat 4-12, Al-Qur'an Dan Terjemahannya, (Mujamma' Malik Fahd: Madina KSA, $1418 \mathrm{H}$ )

8 Ibnu Katsir. Tafsir Al-Qur'an Al'Azhim, (Dar Al-Aqidah;Mesir, 2010) Jilid 4, Hlm. 608 
keimanan, selalu istiqomah dan berdakwah dijalannya serta bersabar atas ujian keimanannya. Keyakinan akan pertolongan Allah menjadikan ia tidak pernah berhenti untuk selalu menyampaikan kebenaran yang ia yakini. Sehingga kaumnya banyak yang beriman, meyakini apa yang ia sampaikan serta mengamalkannya.

Hamka dalam tafsirnya Al-Azhar menjelaskan bahwa ajaran tauhid menyebabkan keyakinan kepada Allah tidak dapat berbelah bagi. Manusia beriman tidak akan tunduk kepada sesama manusia, seperti ketundukan dia kepada Allah. Dengan keyakinan tauhid, manusia sampai kepada kesimpulan bahwa yang gagah itu hanya Allah; adapun manusia tidaklah gagah perkasa. Manusia tidak sanggup melawan penyakit, tidak sanggup melawan tua atau melawan maut.Allah maha terpuji karena hanya Dia sajalah yang benar-benar berjasa atas alam ini dan tidak pernah bersalah. ${ }^{9}$

Konsep tauhid dalam kisah Ashabul Ukhdud nampak pada keteguhan terhadap keyakinan yang kuat bahwa hanya Allah saja yang wajib ditaati. Adapun selain Allah meskipun mempunyai kekuasaan dan kekuatan harus ditinggalkan. Tidak sebanding dengan Allah yang Maha Perkasa, yang memiliki kerajaan langit dan bumi. Ujian penyiksaan yang menimpa Ashabul Ukhdud merupakan rangkaian keimanan yang tidak lepas dari orang beriman. Orang beriman akan diuji keimanannya seberapa kuat keyakinannya kepada Allah. Keyakinannya terhadap janji Allah terhadap orang beriman dan ancaman Allah terhadap orang yang tidak taat, membangkang dan sombong.

Pendidikan tauhid membawa manusia kepada kondisi awal ketika ia diciptakan yaitu fitrah. Fitrah manusia ketika ia diciptakan adalah tauhid. Maka tauhid yang benar itu beribadah kepada Allah tanpa mensekutukanNya dengan apapun. Itulah maksud diciptakannya manusia dan

9 Hamka.Tafsir Al-Azhar, (Gema Insani, Jakarta; 2015) Jilid 9, Hlm. 537 jin didunia ini. Allah berfirman, "tidaklah Aku ciptakan jin dan manusia kecuali untuk beribadah kepadaKu." Muhammad bin Abdul Wahhab menjelaskan makna beribadah dalam ayat ini yaitu bertauhid. ${ }^{10} \mathrm{Hal}$ ini selaras dengan unsur-unsur pendidikan yang dipaparkan oleh An-Nahlawi bahwa unsur pertama pendidikan adalah menjaga dan memelihara fitrah, serta mengarahkan fitrah tersebut dan semua potensi yang sesuai menuju yang lebih baik dan sempurna. Sedangkan menurut muthoifin dalam penelitiannya menyimpulkan bahwa isi dan inti dari pendidikan adalah sebagaimana yang ada dalam surat al-Ashr ayat 1-5 yaitu mengandung 5 (lima) unsur yang harus diaplikasikan secara bersamasama, yaitu: 1. Unsur keimanan, 2. Unsur keilmuwan, 3. Unsur amaliyah, 4. Unsur akhlak, dan 5. Unsur sosial. Dan ternyata kelima unsur ini harus ada dan berjalan secara beriringan, dinamis, utuh, tidak parsial, dan saling melengkapi. ${ }^{11}$

\section{METODE PENELITIAN}

Metode penelitian ini merupakan metode kualitatif. Proses penelitian ini dititikberatkan pada metode diskriptif, induktif dan analisis isi. Karena penelitian ini tidak dapat diukur oleh angka, yang diukur adalah nilai yang tidak dapat diukur dengan pasti. Analisis induktif yaitu menganalisa isi dari obyek penelitian dengan mengambil permisalan-permisalan yang ada kemudian dirumuskan dalam satu pengertian yang lain, yang menyeluruh dan lebih sederhana.

Penelitian ini terbatas pada ruang

10 Muhammad bin Abdul Wahhab. Ushuluts Tsalasah Waadillatuha, (Kementrian Urusan Islam,Wakaf, Dakwah dan Bimbingan, Arab Saudi: 1420 H) hlm. 8

11 Muthoifin. Mengungkap Isi Pendidikan Islam Perspektif Al-Qur'an Surat Al-Ashr Ayat 1-3 dalam https://scholar.google.co.id/citations?user $=6$ rI6mtoAAAAJ $\& \mathrm{hl}=\mathrm{en} \# \mathrm{~d}=\mathrm{gs} \_\mathrm{md} \_\mathrm{ci}-$ ta-d\&u=\%2Fcitations $\% 3$ Fview_op $\% 3$ Dview citation $\% 26 \mathrm{hl} \% 3 \mathrm{Den} \% 26 \mathrm{user} \% 3 \mathrm{D} 6 \mathrm{rI} 6 \mathrm{~m}-$ toAAAAJ\%26citation_for_view\%3D6rI6mto AAAAJ\%3AV_vSwabWVtYC\%26tzom \%3D-420 
lingkup pendidikan agama Islam, tidak termasuk didalamnya penelitian pendidikan secara umum. Demikian juga, penelitian ini berbasis pada penelitian perpustakaan (library research). Karena datadata penelitian baik yang primer maupun sekunder bersumber dari perpustakaan. Tipe yang digunakan dalam penelitian ini tipe deskriptif yaitu mendeskripsikan secara terperinci data-data temuan dengan memberikan penilaian dan kesimpulankesimpulan sesuai dengan sudut pandang pendidikan Islam dan pendekatan sejarah.

Karena penelitian ini berbasis pada penelitian perpustakaan (library research), oleh karena itu maka data yang dipakai adalah data berupa dokument, baik karya tulis, jurnal, makalah maupun dokument berupa skripsi, tesis dan disertasi. Sumber data penelitian ini dibagi dua, pertama sumber data primer yaitu data yang menjadi fokus penelitian untuk diobservasi yaitu kitab Tafsir Ibnu Katsir, tafsir Al-Azhar dan kitab sejarah selanjutnya dianalisa secara seksama.

Kedua, data sekunder yaitu data yang menjadi pendukung dari data primer, menjelaskan secara detail dan mendeskripsikan sesuai dengan sudut pandang dan pendekatan penelitian. Data sekunder berupa kitab aqidah dan tauhid, buku-buku pendidikan Islam, hadist, kitabkitab sejarah seperti Al-Bidayah Wan Nihayah karya Ibnu Katsir, kitab yang membahas tentang ilmu tafsir, serta data-data yang mendukung dalam proses penelitian.

Sedangkan untuk menganalisis data kualitatif ini penulis menggunakan teknik deskriptifanalitik, yaitu teknik mengumpulkan dan menyusunnya kemudian menganalisis dan menafsirkan data yang sudah terkumpul serta memaparkan kesimpulan kesimpulan hasil analisa. Teknik ini dilakukan untuk memudahkan peneliti dalam proses penganalisisan data dengan menggunakan landasan teori yang telah ditetapkan sebelumnya sebagai alat analisis data.

Untuk mempermudah pemahaman dan agar penelitian ini dapat terfokus pada pokok studi maka sistematika pembahasan di dalam penyusunan penelitian ini dibagi ke dalam limalangkah. Langkah pertama, berisi latar belakang masalah yang mengarahkan pembaca mengapa penelitian ini layak untuk dilakukan. Dalam langkah ini juga disebutkan tentang rumusan masalah, tujuan dan kegunaan penelitian, telaah pustaka. Demikian juga menjelaskan tentang metode penelitian yang digunakan dalam penulisan penelitian ini serta sistematika pembahasan.

Langkah kedua, memaparkan tentang kerangka teoritik pendidikan Islam;pengertian, unsur-unsur dan karakteristik pendidikan Islam. Selanjutnya pendidikan tauhid, makna dan pengertian, urgensi tauhid dan konsep tauhid dalam pendidikan. Selanjutnya kisah Ashabul Ukhdud, siapa mereka, asal usul mereka dan waktu terjadinya kisah tersebut.

Langkah ketiga menjelaskan tentang konsep tafsir Al-Qur'an, tafsir Ibnu Katsir dan tafsir Al-Azhar yang menjelaskan tentang biografi kedua mufassir, karakteristik masing-masing kitab tafsir tersebut serta karya-karya besar mereka. Langkah keempat memaparkan data beserta hasil analisis tentang pendidikan tauhid dalam kisah Ashabul Ukhdud. Pada bab ini uraian difokuskan kepada konsep pendidikan tauhid dalam kisah Ashabul Ukhdud menurut tafsir Ibnu Katsir dan tafsir Al-Azhar. Selanjutnya menjelaskan tentang implikasi konsep pendidikan tauhid dalam kehidupan individu, keluarga dan masyarakat.Langkah kelima, penutup yang berisi tentang kesimpulan, saran dan rekomendasi.

\section{HASIL PENELITIAN DAN PEMBAHASAN}

Konsep pendidikan tauhid dalam kisah ashabul ukhdud sesuai dengan landasan teori, dapat di bagi menjadi tiga bagian. Pertama konsep pendidikan tauhid rububiyah yang mencakup, fitrah sebagai dasar pendidkan tauhid, alam semesta sebagai sarana pendidikan tauhid, reward dan punishment dalam pendidikan tauhid. 
Fitrah diartikan dengan citra asli yang dinamis, yang terdapat pada sistemsistem psikofisik manusia, dan dapat diekspresikan dalam bentuk tingkah laku. Citra unik tersebut telah ada sejak awal penciptaannya. Hasil kajian dari kisah Ashabul Ukhdud baik dalam tafsir Ibnu Katsir maupun tafsir Al-Azhar memberikan gambaran bahwa fitrah manusia itu bertauhid dari sejak kecil. Hal ini nampak jelas pada akhir kisah yang disebutkan didalam hadist muslim. Yaitu ketika seorang bayi yang masih dalam gendongan, pada masa-masa menyusui berkata kepada ibunya yang ragu untuk terjun kedalam parit api karena ia khawatir akan bayinya. اصبري يا أمه فإنك على الحق "Wahai ibu bersabarlah karena engkau di atas kebenaran", bayi itu berkata kepada ibunya dalam usia yang tidak mungkin ia sudah bisa berbicara untuk terjun ke parit karena ibunya dalam kebenaran. Hal ini menunjukkan fitrah si bayi masih dalam keadaan bertauhid, ia menyatakan kebenaran apa yang di jalankan ibunya sedangkan dia sendiri belum memahami apa yang sedang terjadi.

Ibnu Katsir menjelaskan ayat seratus tiga puluhdari suratAr-Rum sebagaiberikut; luruskanlah wajahmu dan teruslah diatas apa yang disyariatkan Allah bagimu, seperti millah Ibrahim yang lurus, yang Ia tunjukkan untuk mengikutinya, menyempurnakannya dengan sesempurnanya. Jika engkau demikian maka telah berpegang teguh pada fitrah yang bersih.Yang telah Allah tetapkan pada semua makhluk sejak awal diciptakan. Allah menciptakan makhluknya sudah dalam keadaan berma'rifah dan bertauhid kepadaNya tidak ada illah selain Dia. Sebagaimana perkataan Allah, "dan Allah mengambil kesaksian terhadap jiwa mereka (seraya berfirman): "Bukankah Aku ini Tuhanmu?" Mereka menjawab: "Betul (Engkau Tuhan kami)." Dalam sebuah hadist qudsi Allah berkata: "Sesungguhnya Aku menciptakan hambahambaku dalam keadaan lurus, maka syaithan menyelewengkan mereka dari agamanya." ${ }^{12}$ Hadis ini menjelaskan bahwa 12 Muslim, Shahih Muslim, ( Riyadh: Dar Al-Had-
Allah mencipatakan makhluk dalam fitrah yaitu Islam.Akan tetepi masuklah kedalam fitrah mereka agama-agama yang merusak seperti Yahudi, Nasrani dan Majusi. ${ }^{13}$

Fitrah merupakan suatu kemampuan dasar berkembang (potensi) manusia yang dianugerahkan Allah kepadanya.Didalamnya terkandung berbagai komponen psikologis seperti kecenderungan, bakat dasar, naluri alami, yang satu sama lain saling berkaitan dan saling menyempurnakan bagi hidup manusia. Salah satu komponen tersebut yaitu kemampuan dasar untuk beragama, faktor iman merupakan inti potensi untuk beragama. ${ }^{14}$ Potensi fitrah senantiasa terbuka untuk menerima pengaruhpengaruh eksternal yang muncul.Agar fitrah bisa berkembang dan berubah sesuai dengan potensinya. Bahkan ia tidak akan berkembang sama sekali jika tidak ada pengaruh ekternal yang merubahnya.

Ibnu Taimiyyah menegaskan bahwa tidak seharusnya anak yang terlahir dalam keadaan fitrah itu ketika ia lahir langsung yakin terhadap Islam secara perbuatan. Bahwa Allah mengeluarkan kita dari perut ibu kita dalam kondisi tidak mengetahui apa pun. Akan tetapi bersihnya hati, penerimaanya dan keinginannya kepada kebenaran yaitu Islam.Jika itu dibiarkan tanpa ada satupun yang mempengaruhinya niscaya tetap dalam Islam. Beliau melanjutkan, Sesungguhnya fitrah itu mengandung ikrar kepada Allah dan condong kepadaNya. Inilah makna laa ilaha illallah, bahwa illah adalah Dia yang di kenali dan diibadahi. ${ }^{15}$

Dipahami dari pernyataan Ibnu Taimiyah bahwa fitrah yang ada pada diri manusia sejak ia diciptakan harus melalui proses usaha pendidikan. Karena

harah, 2015) hadist no. 2865

13 Ibnu Katsir, Tafsir Al-Quran Al-'Azhim, ( Beirut: Dar Al-Kutub Al-Ilmiyah, 1998), jilid 6, hlm. 282

14 M. Arifin, Ilmu Pendidikan Islam, (Jakarta: Bumi Aksara, 1996), hlm. 97-99

15 Saad Ali Abdul lathif, At-Ta'rifaat Al-I'tiqodiyah (Madar Al-Wathan; Riyadh, 2011), hlm. 256 
pada dasarnya manusia lahir tidak mengetahui apapun.Allah memberikan saran dalam usaha pendidikan untuk bisa mengembangkan fitrah yang ada pada dirinya.

Selanjutnya, alam semesta sebagai sarana pendidikan tauhid, bukanlah musuh manusia dan bukan pula halangan untuk kemajuannya. Bahkan sebaliknya sebagai sarana terbaik untuk kemajuan dan sangat berguna dan bermanfaat bagi manusia. Allah menyatakan dalam ayat Sembilan dari surat Al-Buruj yang artinya, "Yang mempunyai kerajaan langit dan bumi; dan Allah Maha Menyaksikan segala sesuatu."16 Demikian juga alam semesta menjadi objek untuk berfikir dan menganalisa dari sisi intelektual, serta kenikmatan bagi kehidupan seni dan spiritual. Dengan berfikir dan menganalisa, manusia mampu mengungkap perbendaharaan alam. Sanggup menampakkan keindahan yang menakjubkan memberikan bukti yang jelas wujud sang pencipta keindahan, Allah Yang Maha Esa. ${ }^{17}$

Tujuan alam semesta sebagai sarana pendidikan tauhid ialah agar manusia sebagai pelaku pendidikan mengetahui bahwa kekuasann Allah itu mutlak, ilmuNya mutlak dan kasih sayangNya juga mutlaq. Alam semesta merupakan tempat eksperimen bagi manusia untuk membuktikan keabsahan apa-apa yang tercantum dalam wahyu. Sehingga manusia semakin yakin akan kebenaran yang dibawa oleh Nabi Muhammad Saw. Manusia melihat penciptaan alam semesta sangatlah detail, baik hukumnya, peraturannya, bentuknya serta pergerakannya. Dari sinilah terbuktinya keagungan proses pendidikan ilahi (tarbiyah ilahiyyah) terhadap manusia, hewan, tumbuh-tumbuhan dan bendabenda lainnya. Proses pendidikan ilahi ini jika diteliti oleh manusia dengan akal dan inderanya maka ia akan mengetahui makna

16 Al-Qur'an Surat Al-Buruj ayat 9, Al-Qur'an dan terjemahannya, (Mujamma' Malik Fahd: Madina KSA, $1418 \mathrm{H}$ )

17 Hasan Langgulung, Asas-Asas Pendidikan( Pustaka Al-Husna: Jakarta , 1987) hlm. 52. rabbul 'alamin serta yakin dengan wahyu yang datang padanya. Manusia juga akan mengetahui bahwa Allah sajalah yang Maha Esa tiada sekutu bagiNya dalam cinta dan ibadah. ${ }^{18}$

Alam semesta mendorong manusia untuk melembutkan hati, memuji Allah, mensyukuri nikmat Allah bertasbih dan bertauhid kepadaNya, serta mendidik daya afeksi dan emosianal manusia untuk tunduk kepada Allah. Akal manusia terdidik untuk terbiasa dengan kondisi ilmiah, artinya ia menggunakan prinsip praktis dan penggunaan kaidah-kaidah ilmiah dalam mengelola potensi alam untuk kesejahteraan manusia. ${ }^{19}$

Reward dan punsihment dalam pendidikan tauhid sewajarnya dilakukan sebagai standar pendidikan Islam. Rewoard dan punishment menjadi salah satu metode pendidikan yang efektif diterapkan kepada peserta didik. Metodeinimendorong peserta didik untuk belajar suatu bahan pelajaran atas dasar minat (motif) dengan kesadaran pribadi, terlepas dari paksaaan atau tekanan mental. Belajar dengan dasar motif yang bersumber dari kesadaran pribadi, dipandang oleh ahli psikologi sebagai suatu kegiatan positif yang membawa keberhasilan proses pendidikan. ${ }^{20}$ Allah menggambarkannya dalam ayat 10-11 dari surat Al-Buruj, "“Sesungguhnya orang-orang yang mendatangkan cobaan kepada orang-orang yang mukmin laki-laki dan perempuan kemudian mereka tidak bertaubat, maka bagi mereka azab Jahannam dan bagi mereka azab (neraka) yang membakar.Sesungguhnya orang-orang yang beriman dan mengerjakan amal-amal yang saleh bagi mereka surga yang mengalir di bawahnya sungai-sungai; itulah keberuntungan yang besar." 21

18 Majid Arsalan Al-Kailani. Falsafatut Tarbiyah Al-Islamiyah, (Dar Al-Manarah: Jeddah, 1989) hlm. 116.

19 Abdurrahman An-Nahlawi, Pendidikan Islam (Gema Insani Pres: Jakarta, 1995), hlm. 54

20 M. Arifin, Ilmu Pendidikan Islam (Bumi Aksara: Jakarta, 1996) hlm. 210

21 Al-Qur'an Surat Al-Buruj ayat 10-11, Al-Qur'an Dan Terjemahannya, (Mujamma' Malik Fahd: Madina KSA, 1418 H) 
Relevansi pendidikan tauhid sangatlah kuat bahkan tidak bisa dipisahkan sama sekali dengan metode targhib dan tarhib. Karena ia menjadi metode yang digunakan dalam Al-Qur'an maupun hadist dalam mendidik kaum mukminin untuk senantiasa dalam keimanan. Dalam masalah tauhid, Allah mengancam orang-orang yang berbuat syirik akan mendapatkan dosa besar, ${ }^{22}$ haram masuk surga, ditempatkan dineraka serta tidak mendapat pertolongan Allah. ${ }^{23}$

Kedua, konsep pendidikan tauhid uluhiyyah mencakup peran pendidik dalam pendidikan tauhid, evaluasi dalam pendidikan tauhid dan pendidikan sepanjang hayat. Pendidik dan guru dalam pendidikan tauhid mengacu pada konsep ulul al-bab, al-ulama', al-muzakki, ahl aldzikir dan al-rasihun fi al-ilm, maka ia akan menempatkan dirinya bukan hanya sebagai sosok unsur pembelajaran yang tunduk pada hukum transaksional. Akan tetapi sebagai pengemban misi suci para Rasul, penyelamat manusia dari kebinasaan, meluruskan manusia dari penyelewengan tauhid, membangun peradaban masa depan baik masa depan duniawi maupun ukhrawi. ${ }^{24}$

Ghulam dalam kisah ashabul ukhdud merupakan seorang yang alim, yang belajar agama nasrani dengan benar dari seorang rahib. Ini merupakan ajaran tauhid murni dari ajaran Nabi Isa. Ghulam merupakan seorang pendidik dan guru yang mengajarkan ummatnya tentang kebenaran agama tauhid. Sebagai seorang pendidik, ia memiliki sifat dan karakter sebagaimana disebutkan Ibnu Sina. Yaitu pandai, bagus agamanya, mampu mendidik akhlak, berbobot, teguh pendirian, tidak

22 Rasulullah bersabda: "maukah kalian saya beritahu dosa yang paling besar - tiga kali- ",Sahabat berkata: "iya wahai Rasulallah", beliau melanjutkan: "syirik kepada Allah dan durhaka kepada orang tua. "Shahih Bukhari, (Dar As-Syaeb: Kairo, 1987) kitab bad'u wahyi, nomor hadist 2654.

23 Surat Al-Maidah ayat 72

24 Abudin Nata, Kapita Selekta Pendidikan Islam (Rajawali Press: Jakarta, 2013),hlm. 307 kaku, murah senyum, cerdas, punya harga diri dan menjaga kebersihan serta terhindar dari syubhat. ${ }^{25}$

Pendidik dan guru dalam pendidikan tauhid juga harus memiliki sifat yang sangat urgen dalammenjalankan proses pendidikan tauhid, yaitu rabbani. Makna dari rabbani adalah seorang yang berilmu, bijaksana, lemah lembut, pendidik dan guru manusia, menguasai ilmu-ilmu yang dasar sebelum ilmu-ilmu yang lebih tinggi, mengajak memperdalam ilmu, mengamalkannya serta mengajarkannya kepada orang lain, itulah kunci kebahagiaan, jika hilang unsurunsur itu maka akan terjadi degradasi dan disfungsi makna rabbani. ${ }^{26}$ Yusuf AlQardhawi mendefinisikan rabbani dengan ikatan yang baik dan kuat kepada Allah (tauhid), mengetahui agama dan kitabNya, serta mengajarkannya kepada orang lain, agar mendapatkan keridhaan Allah, inilah tujuan hidup manusia. ${ }^{27}$

Selanjutnya, evaluasi dalam pendidikan tauhid tercermin pada sistem evaluasi yang Allah sebutkan dalam Al-Qur'an, ia bersifat makro dan universal. Dengan menggunakan tehnik testing mental atau psikotes, yang menitikberatkan pada sikap, perasaan dan pengetahuan manusia seperti iman dan kekafiran, ketaqwaan dan kefajiran (kognotif afektif). Allah menyatakan dalam ayat delapan dari surat Al-Buruj, "Dan mereka tidak menyiksa orang-orang mukmin itu melainkan karena beriman kepada Allah Yang Maha Perkasa lagi Maha Terpuji". Allah mengevaluasi iman orang beriman dengan memberikan ujian berupa keganasan orangorang kafir terhadap mereka.

Adapun sistem pengukuran (measurement) yang digunakan tidak menggunakan sistem laboratorium seperti dalam dunia modern sekarang. Namun

25 Abu Lubabah Husain. At-Tarbiyah fi As-Sunnah An-Nabawiyah, (Dar Al-Liwa': Riyadh tanpa tahun), hlm 48.

26 Abdurrahman As-Sa'di, Taisir Karimur Rahman (Dar As-Salam: Riyadh, 2002), hlm. 143.

27 Yusuf Al-Qardhawi, Khashais Al-Islam Al-Ammah, (Bairut: Muassasah Ar-Risalah, 1983), hlm. 9. 
prinsip-prinsipnya menunjukkan bahwa sistem pengukuran terhadap perilaku manusia beriman dan tidak beriman secara umum telah di tunjukkan dalam Al-Qur'an. Misalnya ayat-ayat yang menunjukkan bahwa sifat-sifat orang beriman ialah bila shalat mereka khusyu', berzakat, menjaga kemaluan, seperti yang tercantum dalam surat Al-Mukminun ayat satu sampai lima. Dan masih banyak ayat-ayat yang menunjukkan hal tersebut. ${ }^{28}$

Pelaksanaan evaluasi pendidikan perlu menerapkan prinsip-prinsip dasar yaitu mengacu pada tujuan pendidikan. selanjutnya evaluasi dilakukan secara obyektif berdasarkan fakta dan data, serta evaluator yang memiliki sifat jujur, amanah serta ramah siap menolong. Berikutnya evaluasi harus komprehensif menyeluruh dalam berbagai aspek serta terus menerus berkesinambungan dan berjangka. ${ }^{29}$

Evaluasi dalam pendidikan tauhid merupakan satu sistem proses pendidikan yang harus ada. Evaluasi pendidikan tauhid berfungsi sebagai alat untuk menyeleksi, mendiagnosa serta mengukur keberhasilan prosen pendidikan. Evaluasi tersebut bertujuan untuk mengetahui sejauh mana pemahaman tentang tauhid serta mengetahui hasil pendidikan keimanan kepada Allah dan hari akhir. ${ }^{30}$

Pendidikan tauhid berlangsung sepanjang hayat. dapat dipastikan bahwa seseorang itu tidak akan pernah tamat dari 'bersekolah' sepanjang hayat. Karena banyaknya tuntutan kebajikan yang dalam Al-Qur'an dan sunnah Nabi. Tujuan untuk mencapai manusia seutuhnya (insan kamil) adalah tujuan ideal yang sulit dicapai oleh manusia.Allah menggambarkan pendidikan sepanjang hayat dalamsurat Al-Buruj ayat sebelas, "Sesungguhnya orang-orang yang beriman dan beramal shalih bagi mereka jannah yang mengalir dibawahnya sungai-sungai, itulah kemenangan yang besar". Orang-orang

28 M. Arifin, Ilmu Pendidikan Islam... hlm. 243244

29 Abudin Nata, Filsafat Pendidikan Islam 1... hlm. 140-142

30 M. Arifin, Ilmu Pendidikan Islam... hlm. 240 yang beriman senantiasa selalu beramal shalih, berusaha beramal sebaik-baiknya, menjaga dan mengembangkan tauhid dalam dirinya dengan proses pendidikan sampai akhir hayat, untuk mencapai husnul khatimah.

Manusia dituntut untuk belajar terus menerus tanpa berhenti. Ketika dia berada pada satu tahapan atau stasiun tertentu, maka dia akan lanjut lagi ke stasiun berikutnya. ${ }^{31}$ Dalam konsep pendidikan tauhid, seseorang harus menjaga dan meningkatkan keimanan dan ketakwaan hingga akhir hayat. Karena tauhid menjadi kunci utama seseorang untuk bisa diterima disisi Allah, diridhoiNya dan dijanjikan syurga, serta meraih kemenangan yang hakiki. Untuk mendapatkannya seseorang mesti senantiasa mendidik dirinya dan beramal shalih dalam rangka memperbaiki nilai ketauhidannya kepada Allah. Allah menegaskan dalam Ali Imran ayat 102, "Hai orang-orang yang beriman, bertakwalah kepada Allah sebenar-benar takwa kepada-Nya; dan janganlah sekali-kali kamu mati melainkan dalam keadaan beragama Islam." 32

Ketiga, konsep pendidikan tauhid asma' wasifat. Allah memanifestasikan diri melalui nama-namaNya, agar dijadikan panutan dalam pengembangan potensi-potensi baik dalam diri manusia. Nama-nama Allah bukan hanya menjadi saran untuk mengetahui kemahasempurnaan Allah saja akan tetapi juga untuk mendekatkan diri kepadaNya dengan meneladani sifat-sifatNya. Dalam proses pendidikan manusia dianjurkan untuk mencerminkan akhlaq yang baik sebagaiman Allah memiliki nama-nama yang baik. Seperti sifat berkasih-sayang terhadap sesama muslim dan sesama mahluk, cermin dari nama dan sifat Allah Ar-Rahman dan ArRahim. Rasulullah bersabda:"Orang-orang yang penyayang niscaya akan disayangi pula oleh ar-Rahman (Allah). Maka sayangilah

31 Haidar Putra Daulay, Pendidikan Islam Dalam Perspektif Filsafat (Prenada Media Grup: Jakarta: 2014), hlm. 159-160

32 Bukhari Umar, Ilmu Pendidikan Islam(Amzah: Jakarta, 2010),hlm. 127 
penduduk bumi niscaya Yang di atas langit pun akan menyayangi kalian." 33

Makna dari hadist diatas bahwa manusia dalam proses pendidikan harus ditanamkan atau tertanam dalam dirinya sifat-sifat baik yang tercemin dari Asmaul Husna, seperti kasih sayang, lemah lembut, memaafkan, membantu orang lain, tegas, berprilaku terpuji, sabar, dan lain-lain. Manusia yang terdidik dengan pendidikan ilahi adalah manusia yang memiliki karakter dan sifat ilahi. Secara garis besar tahapan manusia untuk meningkatkan kualitas jiwa dalam menyerap makna hikmah Asmaul Husna terbagi menjadi tiga tingkatan, ta'alluq. takhalluq dan tahaqquq. Ta'alluq pada Allah yaitu berusaha mengingat dan meningkatkan kesadaran hati dan pikiran kita kepada Allah. Sedangkan takhalluq, yaitu menafikan sifat yang ada pada diri sendiri, dan menegaskan sifat-sifat Allah yang secara potensial ada pada diri manusia. Adapun tahaqquq, maknanya benar-benar meresapi makna asmaul husna serta dituntut agar melahirkan sikap dan perilaku seharihari yang sesuai dengan makna asmaul husna tersebut. ${ }^{34}$

\section{PENUTUP}

Penjelasan konsep pendidikan tauhid dalam kisah ashabul ukhdud surat Al-Buruj telaah atas tafsir Ibnu Katsir dan Tafsir AlAzhar membawa pada kesimpulan, bahwa pandangan tafsir Ibnu Katsir dan tafsir AlAzhar relatif sama tidak ada perbedaan yang mencolok dalam menafsirkan surat AlBuruj ayat empat sampai enam belas. Jika melihat dari teori tauhid, maka penafsiran dalam kisah ashabul ukhdud ini memenuhi teori tauhid yang dibagi menjadi tiga bagian yaitu tauhid rububiyyah, tauhid uluhiyyah dan tauhid asma' wasifat.

Nilai pendidikan tauhid rububiyyah yang terkandung didalamnya seperti fitrah manusia sebagai dasar pendidkan tauhid,

33 At-Tirmidzi, Sunan At-Tirmidzi, (Bairut, Dar AlGharb; 1998), hadist no. 1924

34 Amin Muzamiluddin, Nilai-Nilai Pendidikan Akhlak Dalam Asmaul Husna, Skripsi IAIN Ponorogo 2016, hlm. 93-96 ayat kauniah sebagai sarana pendidikan tauhid, Targhib dan tarhib dalam pendidikan tauhid. Nilai pendidikan tauhid uluhiyyah seperti, peran pendidik dalam pendidikan tauhid, evaluasi dalam pendidikan tauhid dan pendidikan sepanjang hayat. Kemudian yang terakhir nilai pendidikan tauhid asma' wasifat.

Implementasi dari nilai-nilai pendidikan tauhid rububiyyah seperti mengembangkan potensi fitrah tauhid, menjadikan alam sebagai sarana pendidikan tauhid dan penerapan metode targhib (reward) dan tarhib (punishman) dalam pendidikan tauhid. Implementasi pendidikan tauhid uluhiyyah seperti, konsep guru ideal dalam pendidikan tauhid, penerapan ujian dalam proses pendidikan dan penerapan model pendidikan sepanjang hayat dalam pendidikan tauhid. Selanjutnya implementasi pendidikan tauhid asma' wasifat yang tercermin didalam kehidupan seorang mukmin dan masyarakat yang islami.

Berdasakan hasil penelitian kepustakaan tentang konsep pendidikan tauhid dalam kisah ashabul ukhdud surat Al-Buruj telaah atas tafsir Ibnu Katsir dan Tafsir Al-Azhar, maka penulis memberikan saran kepada para pendidik khususnya pendidikan tauhid, orang tua, para ustadz dipesantren, murabbi dan masyarakat umum.

Tauhid, mengesakan Allah dalam rububiyyah, uluhiyyah dan asma' washifat, harus terjaga dengan sebaik-baiknya dari segala yang bisa menyelewengkannya. Karena tauhidmerupakan perkara yang sangat pokok dan mendasar bagi kehidupan seorang muslim. Tauhid merupakan penentu seseorang baik di kehidupan dunia maupun akhirat, bahagia atau sengsara, selamat atau celaka.

Kaum muslimin hendaknya mengetahui cara agar tauhid selalu terjaga kemurniannya, bersih dari kotoran-kotoran syirik maka perlu proses, yaitu proses pendidikan tauhid. Pendidikan yang berdasarkan konsep tauhid dalam segala bidang, baik pendidikan agama maupun 
pendidikan umum. Unsur- unsur tauhid harus senantiasa ada dalam setiap proses pendidikan, baik di lembaga pendidikan atau di masyarakat umum.

Kaum muslimin juga hendaknya menjaga dan mengembangkan fitrah (potensi) manusia yaitu tauhid, karena pada dasarnya sejak lahir sudah membawa fitrah tauhid. Dengan menyelenggarakan pendidikan tauhid dari sejak alam rahim sampai ajal tiba. Pada hakekatnya pendidikan tauhid itu berlangsung sampai akhir hayat.

Karya tulis hasil penelitian penulis tentang konsep pendidikan tauhid ini tentunya masih banyak kekurangan disana sini. Oleh karena itu perlu adanya saran dan kritik dari para pembaca agar pembahasan pendidikan tauhid dalam karya tulis ini lebih tajam dan mendalam. Serta membawa manfaat lebih luas untuk kemaslahatan kaum muslimin.

\section{DAFTAR PUSTAKA}

Al-Kailani, Majid Arsalan. 1989. Falsafatut Tarbiyah Al-Islamiyah. Jeddah.Dar Al-Manarah An-Nahlawi, Abdurrahman. 1995. Pendidikan Islam.Jakarta. Gema Insani Pres Al-Qardhawi, Yusuf. 1983. Khashais Al-Islam Al-Ammah. Bairut: Muassasah Ar-Risalah. Al-Utsaimin, Muhammad bin Shalih. 1424. Al-Qaul Al-Mufid. Arab Saudi: Dar Ibn Aljauzy As-Sa'di, Abdurrahman. 2002. Taisir Al-Karim Ar-Rahman. Riyadh: Dar As-Salam.

At-Tirmidzi. 1998. Sunan At-Tirmidzi. Bairut: Dar Al-Gharb

Daulay, Haidar Putra. 2014. Pendidikan Islam Dalam Perspektif Filsafat. Jakarta: Prenada Media Group.

Fauzan, Shalih Bin. 1998. Kitab Tauhid 1. Jakarta, Akafa Press.

Hamka. 2015. Tafsir Al-Azhar. Jakarta: Gema Insani.

Husain, Abu Lubabah. At-Tarbiyah fi As-Sunnah An-Nabawiyah. Riyadh. Dar Al-Liwa'

Katsir, Ibnu. 2010. Tafsir Alquran Al'Azhim. Mesir, Dar Al-Aqidah.

Langgulung, Hasan. 1987. Asas-Asas Pendidikan Islam. Jakarta, Pustaka Al-Husna.

Lathif, Saad Ali Abdul. 2011. At-Ta'rifaat Al-I'tiqodiyah. Riyadh: Madar Al-Wathan

M. Arifin. 1996. Ilmu Pendidikan Islam. Jakarta: Bumi Aksara.

Muslim. 2010. Shahih Muslim. Kairo: Dar Al-Hadist.

Muthoifin. Mengungkap Isi Pendidikan Islam Perspektif Al-Qur'an Surat Al-Ashr Ayat 1-3 dalam https://scholar.google.co.id/ citations?user=6rI6mtoAAAAJ\&hl=en\#d=gs_md_cita-d\&u=\%2Fcitations $\% 3$ Fview_ op\%3Dview_citation\%26hl\%3Den\%26user\%3D6rI6mtoAAAAJ\%26citation_for_ view\%3D6rI6mtoAAAAJ\%3AV_vSwabWVtYC\%26tzom\%3D-420

Muzamiluddin, Amin. 2016. Nilai-Nilai Pendidikan Akhlak Dalam Asmaul Husna, Skripsi IAIN Ponorogo.

Nata, Abudin. 2013. Kapita Selekta Pendidikan Islam. Jakarta: Rajawali Pers

Umar, Bukhari. 2010. Ilmu Pendidikan Islam. Jakarta: Amzah

Yahya, Harun. 2001. Runtuhnya Teori Evolusi, Bandung: Dzikra. 